\title{
Media Sosial dan Word of Mouth dalam Menentukan Keputusan Konsumen Memilih Jasa Modifikasi Motor
}

\author{
Billy Wirawan ${ }^{1}$, Roswita Oktavianti ${ }^{*}$ \\ ${ }^{1}$ Fakultas Ilmu Komunikasi, Universitas Tarumanagara, Jakarta \\ Email: billywirawan21@gmail.com. \\ ${ }^{2}$ Fakultas Ilmu Komunikasi, Universitas Tarumanagara, Jakarta* \\ Email: roswitao@fikom.untar.ac.id
}

\begin{abstract}
The process of communication that exists in the Kevin Speed between Kevin Speed and konsumenya happens online. This study raised the issue of social media and word of mouth in the decision of consumers to choose services modifications. The researchers used two concepts in the conduct of research, namely social media and word of mouth. Word of mouth is a marketing activity that is conducted through individual to individual, either orally, in writing or using electronic communications that connect the internet based on the experiences about a product and services. The definition of consumer decision defining the decision as a choice or action of the two alternative options or more. In conducting the study, researchers used a qualitative approach with case study method workshop Kevin Speed, Jakarta Barat. The subject of this research is companies that serve the automotive services modification of the motor and the object of this research is the consumer's decision to choose the services of the modifications in the workshop Kevin Speed. In collecting the data the researcher used interview and observation techniques. The results of this research is to make the consumers know how to modify the motor that is true and also consumer help services modification motor in the conduct of marketing through word of mouth in the decision. In this study, researchers also found the results of the consumer both referenced by his friend and see social media services modification of the motor before making a decision.
\end{abstract}

Keywords: determining consumer, social media, word of mouth

\begin{abstract}
Abstrak
Proses komunikasi yang terjalin di dalam Kevin Speed antara Kevin Speed dan konsumenya terjadi secara online. Penelitian ini mengangkat persoalan mengenai media sosial dan word of mouth dalam menentukan keputusan konsumen memilih jasa modifikasi. Peneliti menggunakan dua konsep dalam melakukan penelitian, yaitu media sosial dan word of mouth. Word of mouth adalah kegiatan pemasaran yang dilakukan melalui individu ke individu baik secara lisan, tertulis atau menggunakan komunikasi elektronik yang terhubung internet dengan didasari oleh pengalaman tentang suatu produk dan jasa. Definisi keputusan konsumen mendefinisikan keputusan sebagai sebuah pilihan atau tindakan dari dua pilihan alternatif atau lebih. Dalam melakukan penelitian peneliti menggunakan pendekatan kualitatif dengan metode studi kasus workshop Kevin Speed Jakarta Barat. Subjek penelitian ini adalah perusahaan otomotif yang melayani jasa modifikasi motor dan objek penelitian ini adalah keputusan konsumen memilih jasa modifikasi dalam workshop Kevin Speed. Dalam mengumpulkan data peneliti menggunakan teknik wawancara dan observasi. Hasil penelitian ini adalah membuat konsumen mengetahui cara memodifikasi motor yang benar dan konsumen juga membantu jasa modifikasi motor dalam melakukan pemasaran melalui word of mouth dalam menentukan keputusan. Dalam penelitian ini peneliti juga menemukan hasil konsumen kedua direferensikan oleh temannya dan melihat media sosial jasa modifikasi motor sebelum menentukan keputusan.
\end{abstract}


Kata Kunci: keputusan konsumen, media sosial, word of mouth

\section{Pendahuluan}

Di jaman yang serba digital dan teknlogi modern, banyak sekali perubahanperubahan yang timbul akibat adanya perkembangan teknologi dan penyesuaian terhadap kebiasaan masyarakat tidak terkecuali pada bidang komunikasi oleh sebab itu dijaman sekarang banyak masyarakat yang menggunakan media sosial dalam menjalani kesehariaanya.

Dalam mengumpulkan data peneliti menggunakan konsep sebagai acuan untuk mengumpulkan data, ada dua konsep yang peneliti gunakan. Konsep yang pertama adalah konsep komunikasi media sosial. Media sosial adalah sebuah aplikasi yang memfokuskan pada penggunanya dan memfasilitasi penggunanya dalam beraktifitas maupun membangun relasi dengan masyarakat. Dalam media sosial pemilik akun media bebas mengekspresikan apa saja karena dalam media sosial konten mutlak milik oleh si pemilik akun. (Rulli, 2014).

Proses interaksi yang terjalin di dalam Kevin Speed antara Kevin Speed dan konsumenya terjadi secara online. Berhasil atau tidak menarik minat keputusan konsumen Kevin Speed dapat diukur dan memiliki banyak variabel pendukungnya. Seperti melihat engagement (jumlah interaksi audiens dengan konten media sosial brand), sales (jumlah transaksi penjualan yang dibukukan melalui perantara media sosial dan media online) dan return of investment (hasil yang didapatkan dari investasi kampanye digital).

Konsep kedua yang peneliti gunakan adalah konsep word of mouth. Konsep ini berisi bahwa konsumen lebih percaya kepada word of mouth dari pada iklan.Dalam pemilihan jasa word of mouth lebih cepat diterima oleh konsumen karena informasi yang disampaikan adalah orang yang memiliki hubungan dengan konsumen, seperti kerabat dan keluarga. (Joesyiana, 2018). Definisi keputusan konsumen menurut Kotler, keputusan konsumen adalah proses yang dilalui oleh konsumen dari tahap mengidentfikasi masalah, mengumpulkan informasi, dan pemilihan alternatif sebelum mencapai kesepakatan. Konsep word of mouth dinilai paling efektif dan efisien karena proses interaksi yang terjadi melalui mulut ke mulut. (Nasrullah, 2015).

Kevin Speed adalah sebuah workshop garage yang bergerak dalam bidang otomotif roda dua. Kevin Speed tidak hanya menerima untuk pemasangan accesories part melainkan boreup, dan engine detailing. Dalam membangun sebuah motor Kevin Speed menerima motor 2 tak maupun 4 tak. Kevin Speed menerima berbagai jenis cc motor mulai dari 150cc-1800cc. Workshop Kevin Speed baru ada sejak 18 Januari 2021. Kevin Speed berpusat di Jl. Kejayaan Belakang No.33 RT005/002, Jakarta Barat 11140. Alasan peneliti memilih meneliti perusahaan otomotif Kevin Speed karena peneliti memiliki ketertarikan pada dunia otomotif dan peneliti juga ingin meneliti apakah media sosial dan word of mouth berhasil dalam membantu perusahaan otomotif dalam mengembangkan usahanya.

Rumusan penelitian ini adalah bagaimana media sosial dan word of mouth menentukan keputusan konsumen dalam memilih jasa modifikasi motor. Tujuan penelitian ini adalah untuk mengetahui konsep media sosial dan word of mouth menentukan keputusan konsumen dalam memilih jasa modifikasi motor. 
Billy Wirawan, Roswita Oktavianti: Media Sosial dan Word of Mouth dalam Menentukan Keputusan Konsumen Memilih Jasa Modifikasi Motor

\section{Metode Penelitian}

Pada penelitian ini peneliti menggunakan metode penelitian kualitatif. Menurut David Williams penelitian kualitatif merupakan sebuah cara dalam mengumpulkan data pada suatu latar alamiah, dengan menggunakan metode alamiah dan dilakukan oleh peneliti yang tertarik dengan penelitian alamiah (Dewi, 2019). Dalam melakukan penelitian, peneliti menggunakan strategi studi kasus. Penelitian ini mengambil studi kasus pada konsumen workshop Kevin Speed Jakarta Barat. Penelitian kualitatif merupakan sebuah penelitian yang menghasilkan data yang bersifat deskriptif (gambaran yang berupa kata tertulis maupun lisan dari setiap perbuatan seseorang/ sekelompok masyarakat yang diamati).

Menurut Moleong, subjek penelitian adalah individu yang dipergunakan untuk memberikan informasi terkait mendapatkan hasil situasi dan kondisi saat penelitian (Hassanin, 2014). Pada penelitian ini subjek penelitian adalah perusahaan otomotif yang melayani jasa modifikasi motor. Obyek penelitian menurut Sugiyono adalah sasaran ilmiah yang berguna untuk mencari data untuk kegunaan tertentu tentang suatu hal objektif, valid, dan realiable tentang suatu hal (Yudi, 2013). Pada penelitian ini objek penelitiannya adalah keputusan konsumen memilih jasa modifikasi dalam workshop Kevin Speed.

Dalam melakukan penelitian, peneliti menggunakan dua metode yang pertama melakukan wawancara dan observasi. Peneliti melakukan wawancara kepada ketiga konsumen Kevin Speed. Informan satu, Boed, informan kedua, Enrico Atlansyah, informan ketiga, Ade K Widjaja secara langsung dengan protokol kesehatan. Wawancara dilakukan secara langsung agar mendapatkan data yang lengkap dan mendalam. Jenis wawancara ini dapat menyajikan data yang luas dibandingkan wawancara lainnya. Peneliti melakukan wawancara untuk memperoleh data word of mouth menentukan keputusan konsumen memilih jasa modifikasi.

Menurut Arkianto, observasi yaitu kegiatan pemantauan dan perhatian terhadap suatu obyek dengan menggunakan seluruh indra. Dengan demikian observasi ialah mengamati secara langsung obyek yang diteliti dan kemudian dianalisis (Hartina, 2017). Peneliti melakukan observasi dengan datang langsung untuk melihat pada aktivitas pada workshop Kevin Speed dan media sosial Instagram @ KevinSpeed.jkt. Teknik yang digunakan dalam pemeriksaan data adalah teknik triangulasi. Dalam penelitian ini, peneliti menggunakan teknik triangulasi sumber untuk mendapatkan tingkat keabsahan data yang sesuai.

\section{Hasil Temuan dan Diskusi}

\section{Media Sosial dalam Menentukan Keputusan Konsumen}

\section{a. Jaringan Media Sosial Kevin Speed}

Media sosial Kevin Speed membantu konsumenya dalam membentuk jaringan diantara konsumen dengan Kevin Speed ataupun sesama konsumen agar sama- sama saling mengenal dan menambah relasi diantara konsumen. Media sosial Kevin Speed juga menghubungkan dengan market place dari Kevin Speed untuk memudahkan konsumen dalam membeli produk yang ditawarkan. Menurut Nasrullah, jaringan adalah infrasturktur yang menghubungkan antara gadget dengan sebuah aplikasi lainnya (Rulli, 2014). 
"Cukup si ya, apalagi ada linknya juga untuk nyambung ke marketplace lainnya biar langsung bisa di cek informasinya dan semuanya juga lengkap." (Enrico Atlansyah, konsumen 2)

\section{b. Informasi Jasa yang Diberikan Kevin Speed}

Menurut Nasrullah informasi Informasi menjadi entitas penting di media sosial karena pengguna media sosial mengkreasikan representasi identitasnya, memproduksi konten, dan melakukan interaksi berdasarkan informasi (Rulli, 2014). Dengan penyebaran informasi yang cepat melalui media sosial Kevin Speed merupakan suatu keunggulan di tengah pandemi seperti ini, karena semua orang dibatasi kegiatanya untuk berpergian keluar rumah jadi mau konsumen atau masyarakat mengetahui tentang cara memodifikasi motor dan untuk konsumen, konsumen mengetahui perkembangan pengerjaan motornya.

"Ya bagi saya cukup-cukup bermanfaat ya setidaknya dari apa yang tadinya saya ngga tau, ini sebagai contoh ada part part tertentu kegunaannya apa lalu kemudian apa yang mempengaruhi dengan hal setelah memasang part tersebut apa, kalau bagi saya si cukup ya cukup bermanfaat." (Ade K Widjaja, konsumen 3)

\section{c. Interaksi Pihak Kevin Speed dengan Konsumen}

Menurut Nasrullah interaksi Media sosial membentuk jaringan antar pengguna yang tidak sekedar memperluas hubungan pertemanan melainkan media sosial tersebut digunakan untuk memperkenalkan suatu produk agar dapat dikenal lebih luas oleh (Rulli, 2014).Peneliti dalam melakukan penelitian menemukan ada beberapa dari konsumen yang menyimpan foto atau video dari unggahan media sosial Kevin Speed. Dalam pemanfaatanya Kevin Speed menggunakan media sosial untuk memperkenalkan produk dan jasa yang dijual media sosial Kevin Speed cukup aktif dalam menggungah konten yang cukup interaktif seperti pengerjaan motor konsumen dan membalas pesan dari konsumen dengan cepat dan sopan.

"Oh pernah pernah pernah kalau yg memang disitu saya liat juga di medsos tersebut adminnya cukup responsif gitu loh dijawab dengan baik, apa yang kita mau tau bisa dipenuhi ya kenapa engga saya bisa rekomen juga ke temanteman gitu." (Ade K Widjaja, konsumen3)

\section{d. Penyebaran Konten Yang dilakukan Oleh Konsumen Kevin Speed}

Menurut Nasrullah penyebaran tidak hanya menghasilkan konten yangdibangun dan dikonsumsi oleh penggunanya, tetapi juga didistribusikan oleh pemilik akun (Rulli, 2014). Dalam penggunaan media sosial, Kevin Speed tidak hanya mengunggah foto melainkan video.

"Pernah bro, waktu itu motor gw yang diuplod makanya gw share lagi ke temen gw biar temen gw tau motor gw lagi di bengkel." (Boed, konsumen 1)

Dalam penelitian yang dilakukan oleh Fahmi Anwar menemukan kesamaan dengan penelitihan yang dilakukan oleh peneliti. Dalam penggunaan media sosial baik Kevin Speed atau konsumen sama-sama menggunakan etika dalam berkomunikasi dan mengenai tentang keuntungan dan kerugian dalam menggunakan 
Billy Wirawan, Roswita Oktavianti: Media Sosial dan Word of Mouth dalam Menentukan Keputusan Konsumen Memilih Jasa Modifikasi Motor

media sosial pada penelitian terdahulu, yang dilakukan oleh Fahmi Anwar menemukan keuntungan yang didapat dalam menggunakan media sosial lebih besar daripada kerugian (Anwar, 2017). Penemuan tersebut sama dengan yang didapat oleh peneliti keuntungan penggunaan media sosial lebih besar dibandingkan kerugiannya.

\section{Word of Mouth dalam Menentukan Keputusan Konsumen Kevin Speed}

a. Kosumen Menyukai Produk atau Jasa Kevin Speed

Menurut Sernovitz konsumen membicarakan produk atau jasa karena mereka menyukai produk atau jasa yang dibuat (Joesyiana, 2018). Dari hasil penelitian peneliti menemukan informan 1 dan 3 menyukai produk atau jasa yang ditawarkan oleh Kevin Speed.

"Dari pengalaman gw dari cerita temen gw dan dari apa yang gw liat sih makanya gw jadi percaya."(Boed, konsumen 1)

"Karena kalau saya dapet masukan atau input dari beberapa teman teman saya yang sebelumnya sudah pernah masuk di kevin speed, disana bengkelnya oke ya, yang mana mereka sangat memahami saya katakan apa keinginan masing masing konsumen, kebutuhan apa, yang sekiranya mungkin terlalu berlebih mereka bisa menyarankan, oh cukup lah ganti ini aja atau cukup lah dimaksimalkan ini aja gitu loh, jadi menurut saya bengkel Kevin Speed ya oke ya gitu loh, engga ya jadi kita juga bisa memangkas budget si, kurang lebih ya seperti itu." (Ade K Widjaja, konsumen 3)

b. Pembicaraan Membuat Konsumen Merasa Terhubung

Menurut Sernovitz word of mouth lebih sering mengarah ke emosi atau perasaan terhadap produk atau fitur produk. word of mouth memiliki efek yang sangat kuat dalam perasaan terhadap produk atau fitur produk. Informan 2 mengatakan mengetahui Kevin Speed dari teman komunitas sepeda motor ketika sedang berbicara otomotif dan rekanya memberikan rekomendasi untuk memodifikasi pada Kevin Speed.

"Karena dari temen ya rekomendasi terus hasilnya juga udah oke dari temen itu jadi ya percaya"(Enrico Atlansyah, konsumen 2)

c. Konsumen Merasa Terhubung dalam Suatu Komunitas

Keinginan untuk menjadi bagian dari suatu kelompok adalah perasaan manusia yang paling kuat. Membicarakan suatu produk adalah salah satu cara kita mendapat hubungan tersebut. Dalam ketiga informan, dua informan mengatakan mengikuti sebuah komunitas motor sedangkan satu informan tidak mengikuti komunitas melainkan hanya hobi memodifikasi roda dua.

"Ikut bro, gw ikut Big Max Indonesia sama Motor Besar Indonesia”"(Boed, konsumen 1) "Oh iya, kita ada, nama komunitasnya ada Booster."(Enrico Atlansyah, konsumen 2)

"Engga, saya hanya penghobi motor aja si ga ikut komunitas-komunitas" (Ade K Widjaja, konsumen 3) 
Boyd menyebutkan ada tiga faktor yang mempengaruhi keputusan membeli atau menggunakan jasa yaitu (Pane, 2018):

a. Faktor Sosial

Pengaruh sosial yang mempengaruhi keputusan membeli atau menggunakan jasa mencakup kebudayaan, subkebudayaan, kelas sosial, referensi dan keluarga. Dalam hasil wawancara pada informan didapat hasil yang sesuai dengan fakor-faktor yang ada dalam faktor sosial seperti, informan berani menentukan untuk memodifikasi motornya pada Kevin Speed karena direfrensikan oleh temanya.

"Karena kalau saya dapet masukan atau input dari beberapa teman teman saya yang sebelumnya sudah pernah masuk di kevin speed, disana bengkelnya oke ya, yang mana mereka sangat memahami saya katakan apa keinginan masing masing konsumen, kebutuhan apa, yang sekiranya mungkin terlalu berlebih mereka bisa menyarankan, oh cukup lah ganti ini aja atau cukup lah dimaksimalkan ini aja gitu loh, jadi menurut saya bengkel Kevin Speed ya oke ya gitu loh, engga ya jadi kita juga bisa memangkas budget si, kurang lebih ya seperti itu" (Ade k Widjaja)

b. Faktor Pribadi

Faktor pribadi dalam hal ini terdiri dari usia dan tahap siklus, pekerjaan, situasi ekonomi, dan gaya hidup.

"Sangat pas di kantong tapi ya tergantung juga ya kadang jasanya emang aga tinggi kalo kita banyak maunya tapi kalau emang kita ngga banyak maunya ya jasanya standar standar ajalah standar bengkel seperti biasanya" (Enrico Atlansyah)

\section{c. Faktor Psikologis}

Faktor psikologis dalam hal ini terdiri dari motivasi, persepsi, pembelajaran, serta keyakinan dan sikap. Dalam penelitian ini informan dua, pertama mendapatkan referensi dari temanya untuk memodifikasi motornya pada Kevin Speed kemudian informan kedua juga melihat media sosial Kevin Speed. Menurut informan 2, Enrico Atlansyah melihat media sosial Kevin Speed

"Dari temen juga, sama liat dari medsosnya juga"(Enrico Atlansyah)

Hal ini juga yang ditemukan dalam penelitian terdahulu yang dilakukan oleh (Febriana \& Setyanto, 2019) yang menemukan adanya kesamaan word of mouth sebagai konsep untuk menarik keputusan konsumen terhadap suatu produk atau jasa.

\section{Gambar 1. Media Sosial Instagram Kevin Speed}

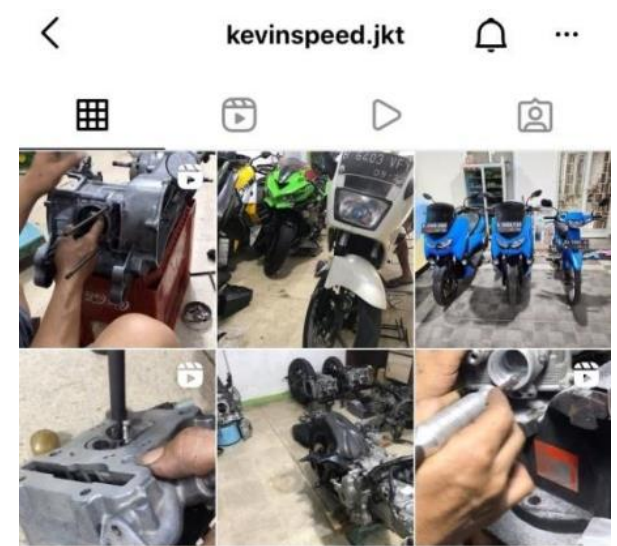

Sumber: Instargram Kevin Speed 
Kevin Speed bergerak menawarkan jasa untuk menaikan kapasitas mesin kendaraan para konsumen. Kevin Speed juga menerima jasa untuk pembuatan noken as untuk semua motor dan rumah roller untuk motor matic.

"Iya kita bergerak dalam bidang jasa modifikasi ya khususnya pada jasa modifikasi mesin, keunggulan kita itu dari pembuatan noken as, buat rumah roller sama mekanik kita kerjanya rapih" (Joseph)

\section{Simpulan}

Dalam media sosial terdapat beberapa karakteristik seperti jaringan, informasi, arsip, interaksi, dan penyebaran. Berdasarkan dengan hasil penelitian yang dilakukan oleh peneliti, menurut konsumen jasa modifikasi motor, media sosial memiliki dampak positif dalam membantu konsumen untuk menentukan keputusan karena dari setiap unggahan foto atau video berisikan informasi mengenai pengerjaan motor setiap konsumen.

Word of mouth keputusan konsumen, dalam Word of mouth terdapat beberapa faktor yang mendorong untuk menentukan keputusan konsumen. Faktor yang pertama mereka menyukai produk atau jasa, kedua pembicaraan yang membuat mereka merasa baik, dan terakhir adalah mereka terhubung dalam suatu kelompok. Dari beberapa faktor yang telah disebutkan dalam penelitian, peneliti menemukan ketiga konsumen mengaku menyukai kendaraan sepeda motor dan suka dalam dunia modifikasi motor.

Dalam menentukan keputusan konsumen, setiap konsumen memiliki beberapa faktor yang mendorong untuk terjadinya sebuah keputusan. Dalam penelitian ini peneliti menemukan hasil media sosial dan word of mouth membantu memperkenalkan produk atau jasa yang ditawarkan kepada konsumennya dan hasil berikutnya yang peneliti dapat konsumen kedua direfrensikan oleh temanya dan baru melihat media sosial sebelum menentukan keputusan.

\section{Ucapan Terima Kasih}

Peneliti ingin mengucapkan terima kasih kepada Fakultas Ilmu Komunikasi Universitas Tarumanagara, narasumber, serta semua pihak yang turut membantu peneliti sehingga penelitian ini dapat diselesaikan.

\section{Daftar Pustaka}

Anwar, F. (2017). Perubahan dan Permasalahan Media Sosial. Jurnal Muara Ilmu Sosial, Humaniora, Dan Seni, 137. https://doi.org/10.24912/jmishumsen.v1i1.343

Dewi, R. P. (2019). Studi Kasus - Metode Penelitian Kualitatif. April 2015, 31-46. https://doi.org/10.31227/osf.io/f8vwb

Febriana, B., \& Setyanto, Y. (2019). Strategi Komunikasi Pemasaran Word Of mouth dalam Meningkatkan Jumlah Pelanggan Coffee Broker. Prologia, 3(1), 39. https://doi.org/10.24912/pr.v3i1.6138

Hassanin, A. (2014). Objek dan Subjek penelitian Metodologi Penelitian. Paper Knowledge. Toward a Media History of Documents, 41-60.

Joesyiana, K. (2018). Pengaruh Word Of Mouth Terhadap Keputusan Pembelian 
Konsumen Pada Media Online Shop Shopee Di Pekabaru (Survey pada Mahasiswa Semester VII Jurusan Pendidikan Akuntansi Fakultas Keguruan dan Ilmu Pendidikan Universitas Islam Riau). Jurnal Valuta, Vol. 4(1), 71-85.

Pane, D. N. (2018). Analisis Pengaruh Bauran Pemasaran Jasa terhadap Keputusan Pembelian Teh Botol Sosro (Studi Kasus Konsumen Alfamart Cabang Ayahanda). Jurnal Manajemen Tools, 9(1), 13-25. http://jurnal.pancabudi.ac.id/index.php/JUMANT/article/view/189

Yudi. (2013). Analisis Food and Beverages Costing Dengan Pendekatan Matriks kaitannya dengan Strategi Pemasaran Pada Olla Restorant Hotel Granada Johor Bahru Malaysia. Journal of Chemical Information and Modeling, 01(01), 1689-1699. 